\title{
Indonesia Industrial Productivity Growth: Evidence of Re-industrialization or De-industrialization?
}

\author{
Lilik Sugiharti', Rudi Purwono ${ }^{1}$, Martha Ranggi Primanthi ${ }^{1}$, Miguel Angel Esquivias ${ }^{1 *}$ \\ 1 Department of Economics, Faculty of Economics and Business, Universitas Airlangga, \\ Jl. Airlangga No.4-6, Airlangga, Surabaya, 60115, Indonesia \\ * Corresponding author, e-mail: miguel@feb.unair.ac.id
}

Received: 12 May 2018, Accepted: 10 June 2019, Published online: 07 August 2019

\begin{abstract}
This study employs a Stochastic Frontier Analysis to decompose Total Factor Productivity for the manufacturing corridor of Indonesia. Technological progress, technical efficiency change, and scale effects are captured at a firm level covering all Java provinces from 2007 to 2013. The period is of particular interest as it covers the efforts of re-industrialization under the Master Plan for Acceleration of Indonesian Economy (MP3EI) and the sharp increase-decrease in global demand and global prices. The study captures sources of productivity growth supporting/deterring output growth, differentiating across firm characteristics based on size (large and medium), technology intensity, skill intensity, location (province), and capital-output ratio employed in production. As firms differ in the five elements, productivity and efficiency performance also differ. This paper questions whether productivity growth is limited to conventional sources -input growth and technological progress-, or if manufacturing is managing some gains through nonconventional channels -technical efficiency and scale effects. The paper also questions the presence of patterns in productivity among group firms (characteristics), finding that firms which combine a low-tech level, a higher skill ratio, and are medium in scale reported TFP at least $70 \%$ higher than the average firm. Combinations of firm size, technology, skills, and ratio output affect the performance. Cost analysis of factors of production is also carried out, finding that energy is canceling out possible gains in scale effects by rising disproportionately both in consumption and prices. TFP growth was found to be negative and falling, raising the possibility of a path towards de-industrialization.
\end{abstract}

\section{Keywords}

Total Factor Productivity, Technical Efficiency, Indonesia, industrialization

\section{Introduction}

From 2000 to 2015, the annual average growth of the Indonesian economy was $5.30 \%$. The labor force expanded by $35 \%$, gross fix capital formation as a percentage of GDP moved from $19.85 \%$ to $32.79 \%$, and the manufacturing sector almost doubled its total value from US\$107.46 billion to US\$212.81 billion. With the expansion of labor (due to a demographic dividend), capital accumulated for the last few decades, and with higher availability of energy and better access to raw materials, it is highly possible that the country has gained from the increase of inputs to support output growth.

However, the possible de-industrialization of Indonesia is often alluded, mainly as manufacturing suffers from low investment, slow growth, inefficiency and low technological upgrading. Industry output decline in the share of national GDP from $27.75 \%$ in 2000 to $20.9 \%$ in 2015 , average electricity prices grew by $208.9 \%$, and electricity consumption almost doubled. Labor absorbed by the sector in $2015(13.6 \%)$ remained at a similar level as that of 2000 (13\%), while labor costs in the last five years grew $27 \%$. In addition, by 2015, $64 \%$ of manufacturers still rely on imported materials. Nine sectors are highly import dependent (textiles, metallurgic, automotive, electronics, chemicals, food, and feeds).

With the expansion of labor, capital accumulation, higher availability of energy and better quality of raw materials, this research questions how much are the booming inputs supporting the expansion of output growth, how much is the rise in prices affecting total production costs, and if the inputs are ever being used more efficiently, reaching gains through non-conventional channels of growth -scale and Technical Efficiency (TE). This study 
estimates TE, the different components of TFP growth, and the share of cost growth per input of production by using a Stochastic Frontier Analysis (SFA) and a flexible nonlinear form at firm level from 2007 to 2013. The study captures differences across firms' factors including location, size, skills, capital, and technology, mainly on the Java island (having the largest population and being the biggest contributor to national GDP). In 2011, the Java Island was proposed as a national industrial corridor under the Masterplan for Acceleration and Expansion of Indonesia's Economy (MP3EI).

This study offers a clear difference and novelty with other empirical evidence. Firstly, the results are presented at three different levels of analysis: by a group of technological intensity (four main groups based on technology), at the industry level (at 2 ISIC level), and at provincial level. Secondly, the study also allows further segmentation of firms based on human skills, firm size, capital-output ratio, location, and technology. Thirdly, the study incorporates an input cost analysis, relevant for countries highly competitive in low-cost sectors.

\section{Literature review}

This research is related to three main empirical issues: 1) the nature of output growth comparing conventional versus non-conventional sources of growth. 2) Total Factor Productivity (TFP) in Indonesian manufacturing and 3) firm characteristics influencing TFP performance.

The conventional growth model (Solow, 1957) distinguishes movements along with the production function caused by growth in inputs and the shift of the production function caused by technical progress (conventional source of output growth). Additional sources of growth consider the possibility of shifts in production due to gains/losses due to scale effects or technical efficiency changes. Total Factor Productivity (TFP) can capture the rate of technological change (TP), a scale component (SC) and a change in technical efficiency (TEC) affecting the production frontier.

Related to the first issue, Li and Liu (2011) and Liu and Li (2012) report input growth as the most significant contributor to economic growth in China, while scale effects and Technological Progress contributed at a lower degree, causing a shift from intensive labor manufacturing to higher tech ones. Liu and Li (2012), estimate TFP in Chinese manufacturing (1999 to 2007), finding human capital as a major source of growth versus labor and capital, with essential contributions from scale effects but a rather small technical efficiency change. Han et al. (2002) found that from 1987 to 1993, growth had been supported in Hong Kong, Singapore, Japan and Republic of Korea by an increase in inputs and, to some extent, by technical efficiency change but there was little evidence in TFP growth due to technological progress. The growth in inputs is larger than the speed growth of value added.

However, references in Indonesia offer instead mixed results, giving the impression of a country relying more on growth of inputs than on scale, TP and TEC as sources of growth, and therefore possibly experiencing de-industrialization (Esquivias, 2018; Sugiharti et al., 2017; Aswicahyono et al., 2010; Margono et al., 2011; Margono and Sharma, 2006; Timmer, 1999). Timmer (1999) estimates that Indonesian manufacturing sectors faced 2.8 percent of TFP growth in the period 1975-1995, similar to those results of Aswicahyono and Hill (2002) of 2.3 percent in 28 Indonesian manufacturing sectors from 1975 to 1993 . However, from 1993 to 2002, TFP growth across Indonesian provinces declined by 7.5 percent due to technical inefficiency (Margono et al., 2011). Saliola and Seker (2011) found that Indonesia experienced a positive aggregate TFP of 0.27 and average TFP of 0.05 in the 20082009 period; however, the elasticity of output with respect to capital was found to be the lowest (0.02), indicating a low contribution of capital to output expansion. The rather mixed results in the Indonesian case open a gap for clarification on the nature of output growth. Also, previous studies of manufacturing in Indonesia mainly differentiate firms by industry, size, location, and ownership (Sari et al., 2016), not covering tech groups, input intensity, or evaluating the role inputs play in cost of production.

Studies at firm level denote the existence of differences in Technical Efficiency (TE) and TFP performance as firms' characteristics differ. Mokhtarul Wadud (2004) finds that TE in Australian textile firms depended on a firm's age, output, capital intensity and legal status; Hill and Kalirajan (1993) find positive correlation with exports, financial integration, and working females; Margono and Sharma (2006) find that location, size and ownership affect TE in some sectors in Indonesia. Sheng and Song (2013) find size, geography and ownership affect TFP in China's iron and steel industry. Oh et al. (2014) find tech level, size, sector, and skills affect TFP performance in South Korea. The three issues open up the question on the nature of growth manufacturing, TFP, and a possible slowdown in Indonesia. 


\section{Methodology}

This study follows the estimation of Liu and Li (2012) on the input effects, cost effects, and the TFP decomposition. This paper applies a stochastic frontier (SFA) model with a Hicks-neutral production function that allows decomposing the sources of growth into the input growth constituent, and the components of TFP growth: scale effect (SE), technical progress (TP) and technical efficiency change (TEC) (Kumbhakar and Lovell, 2003).

The growth due to the input component derives from changes in inputs employed, namely, labor, capital, raw materials, and energy. By using a Hicks-neutral production function, it is possible to relax the assumption of constant returns to scale present in the neoclassical Solow growth model allowing increasing returns to scale. Technical progress (TP) indicates shifts in the production possibility frontier (PPF) under the presence of technological change. Technical efficiency change (TEC) denote changes in a position towards or away from the frontier. TEC will capture changes in the position of firms towards or away from the locus of the PPF which will determine the maximum output that can be attained under the existing technology with the available factors. A firm operating on the frontier is considered technically efficient $(\mathrm{TE}=1)$. Technical inefficiency is allowed through the specification of a non-negative random component in the error term. Both TP and TEC can change over a period of time. Scale effect (SE) captures whether additional inputs can reinforce the effect in output creation by (de)increasing returns. An adjusted scale is computed by multiplying the rate of aggregate input growth and the return to scale minus one (Liu and Li, 2012).

A frontier production function defines the maximum possible output under the existing technology with the input of production. The production function method can estimate TFP growth relaxing the assumption of full TE and allow the decomposition of output growth (Margono and Sharma, 2006:p.981). Technical inefficiency is then added to the conventional production function and estimated simultaneously by the stochastic frontier method (Battese and Coelli, 1995). According to Kalirajan and Shand (1994), the production frontier can be modeled as:

$y_{i t}=f\left(x_{i t}, t ; \beta\right) \cdot \exp \left(v_{i t}-u_{i t}\right)$.

Where $y_{i t}$ is the output of the i'th firm in $t$ period, $x_{i t}$ is a vector of inputs, and $\beta$ is a vector of the parameters to be estimated. The $u_{i t}$ is technological inefficiency in production assumed as a firm-specific, one side error, $u_{i} \geq 0$, independent to $v_{i}$ and $x_{i} . v_{i t}$ is a random error, symmetric and normally distributed $v_{i t} N\left(0, \sigma_{v}^{2}\right)$. While $u_{i}$ is assumed to be half-normal, it can be substituted by a two-parameter gamma (Green, 1990). Aigner et al. (1977) present the likelihood function in the form of two parameters $\left(\sigma^{2}=\sigma_{u}^{2}+\sigma_{v}^{2}\right.$ and $\left.\lambda=\sigma_{u} / \sigma_{v}\right) . \lambda$ indicates the variability of the two sources of error allowing to differentiate one firm from the other. The ML estimator is derived from the maximization of the likelihood function with respect to the parameters $\beta, \lambda$, and $\sigma$. The TE then is based on the expected maximum value of $y_{i t}$ conditional on $\mu_{i t}=0$, and the values of $v_{i t}-u_{i t}$ evaluated using Maximum-Likelihood Estimation (MLE) (Coelli et al., 1998) defined as:

$$
T E_{i t}=\frac{E\left(y_{i t} \mid u_{i t}, X_{i t}\right)}{E\left(y_{i t} \mid u_{i t}=0, X_{i t}\right)}=e^{-u_{0}} \text {. }
$$

Technical Efficiency denotes the maximum possible output with a given input level a firm can produce, denoted by the production possibility frontier (PPP). The stochastic production frontier (SPF) consists of two components: the production function and the composite error terms (statistical and systematic effects specific to the firm). The SPF is then determined by available technology and by external factors. $\mathrm{TE}$ is estimated under an output-oriented approach, picking values between zero and one for the fully efficient firm (Ben-Belhassen and Womack, 2000), measuring the share of actual output relative to the maximum potential output level.

By allowing TP in the TE model the production function at time $t$ for the output $y_{t}$ and inputs $x_{j t}$, turns:

$y_{t}=f\left(x_{1 t}, x_{2 t}, \ldots x_{k t} t\right) e^{(-u t)}$.

Taking the logarithm and differentiating with respect to time, allows the estimation of $\dot{y}_{j t}$ the growth of output; $\dot{x}_{j t}$ the growth of input $\left(x_{j t}\right) ; e_{j t}$ the output elasticity with respect to input $x_{j t} ; \dot{A}_{t}$ technical progress; and $\dot{T E} E_{t}$ the growth of technical efficiency.

$\dot{y}_{t}=\sum_{j} e_{j t} \dot{x}_{j t}+\dot{A}_{t}+\dot{T E} E_{t}$.

By inserting $e_{j t}\left(1 / e_{j t}\right)$ in Eq. (4) as in Liu and Li (2012), we can obtain the share of each input to the total inputs employed in production:

$\dot{y}_{t}=\sum_{j} \frac{e_{j t}}{e_{t}} \dot{x}_{j t}+\left(e_{t}-1\right) \sum \frac{e_{j t}}{e_{t}} \dot{x}_{j t}+\dot{A}_{t}+\dot{T E}$.

The cost share function per input estimated by (Liu and $\mathrm{Li}, 2012)$ as $s_{j t}=\left(e_{j t} / e_{t}\right)$ are inserted into Eq. (5). The output growth is decomposed into input growth denoted as $\left(\dot{\Phi}_{t}\right)$, adjusted scale $\left(e_{t}-1\right) \dot{\Phi}_{t}$, technological progress $\left(\dot{A}_{t}\right)$, and TEC $\left(\dot{T E}_{t}\right)$. 
$\dot{y}_{t}=\sum_{j} s_{j t} \dot{x}_{j t}+\left(e_{t}-1\right) \sum_{j} s_{j t} \dot{x}_{j t}+\dot{A}_{t}+\dot{T E}_{t}$.

From Eq. (6) TFP is derived as

$$
T F P_{t}=\frac{y_{t}}{\dot{\Phi}_{t}}
$$

Assuming $\Phi_{t}$ is the growth of input as $\dot{\Phi}_{t}=\sum_{j} s_{j t} \dot{x}_{j t}$, as in Liu and $\mathrm{Li}$ (2012),

$$
\dot{T F} P_{t}=\left(e_{t}-1\right) \sum_{j} S_{j t} \dot{x}_{j t}+\dot{A}_{t}+\dot{T E} E_{t}
$$

\subsection{The functional form of study}

The SFA can be estimated by any functional form of the production function. Suyanto et al. (2009) suggest using a flexible functional form as it can reduce the risk of errors. The parameters in the equations are estimated employing a stochastic frontier production function in which it assumes that firms deviate from the efficient frontier with random shock (Aigner et al., 1977). As noted in Heriqbaldi et al. (2015) the Hicks-neutral production function is defined as:

$$
\begin{aligned}
\ln \ln Y_{i t} & =\beta_{0}+{ }_{C} \beta \ln \ln C_{i t}+\beta_{L} \ln \ln L_{i t} \\
& +\beta_{R M} \ln \ln R M_{i t}+\beta_{E N} \ln \ln E N_{i t} \\
& +\beta_{t t}+\frac{1}{2}\left[\beta_{C C}\left(\ln \ln C_{i t}\right)^{2}+\beta_{L L}\left(\ln \ln L_{i t}\right)^{2}\right. \\
& \left.+\beta_{R M R M}\left(\ln \ln R M_{i t}\right)^{2}+\beta_{E N E N}\left(\ln \ln E N_{i t}\right)^{2}+\beta_{t t t}^{2}\right] \\
& +\beta_{C L} \ln \ln C_{i t} \ln \ln L_{i t}+\beta_{C R M} \ln \ln C_{i t} \ln \ln R M_{i t} \\
& +\beta_{C E N} \ln \ln C_{i t} \ln \ln E N_{i t}+\beta_{C t} t \ln \ln C_{i t} \\
& +\beta_{L R M} \ln \ln L_{i t} \ln \ln R M_{i t}+\beta_{L E N} \ln \ln L_{i t} \ln \ln E N_{i t} \\
& +\beta_{L t} t \ln \ln L_{i t}+\beta_{R M E N} \ln \ln R M_{i t} \ln \ln E N_{i t} \\
& +\beta_{E N t} t \ln \ln E N_{i t} t+\beta_{R M t} t \ln \ln R M_{i t}+v_{i t}-u_{i t} .
\end{aligned}
$$

where $i=1, \ldots, N$ firm and $t=1, \ldots T ; \ln Y_{i t}$ is the $\log$ for real manufacturing output each $i$ firm at $t$ time. $\ln C_{i t}$ is the $\log$ total fix capital formation, $\ln L_{i t}$ is the $\log$ of the total number of labor, $\ln R M_{i t}$ is the $\log$ of the total amount of raw materials employed, $\ln E N_{i t}$ is the log of cost of energy inputs. The second order terms of log inputs allow for a nonlinear production function.

A generalized likelihood (LR) test is employed as $L R=2[\log L(\hat{\theta})-\log L(\tilde{\theta})], t$ to choose the best functional form. $(\hat{\theta})$ represents the maximum likelihood estimator (MLE) for the unrestricted model, and $(\tilde{\theta})$ denotes the maximum likelihood for the restricted one. The decision to reject the null hypothesis is based on (Verbeek, 2008), when the LT test is bigger than the $\chi^{2}$ distribution value. Five sub-models of functional forms: Hicks-Neutral technological progress, no-technology progress in the production frontier, Cobb Douglas with efficiency model and Cobb Douglas without efficiency model are estimated and tested based on Suyanto et al. (2009). The function fulfills the requirements of monotonicity and quasi concavity. The likelihood ratio test based on (Verbeek, 2008) indicates that the Hicks-Neutral TP has the best fit.

For a general Hicks-neutral model and time-varying TE, TP and SC are stated as in Kumbhakar and Lovell (2003):

$$
\begin{aligned}
T P & =\frac{\partial \ln \ln \left(y_{i t}\right)}{\partial t}=\beta_{t}+\beta_{t t} t+\beta_{i t} \ln \ln c_{i t} \\
& +\beta_{i t} \ln \ln l_{i t}+\beta_{i t} \ln \ln r m_{i t}+\beta_{i t} \ln \ln e n_{i t} . \\
S C & =(e-1) \sum_{j}\left(\frac{e_{j}}{e}\right) \dot{X}_{j} .
\end{aligned}
$$

Where $e_{j}$ measures the relative change in each input owing to a relative change in output. The input growth rate is expressed in $\dot{X}_{j}$. The output elasticity is estimated as the impact of the change in the value of the input of firm $i$ at time $t$ on output (Verbeek, 2008, p. 56):

$\varepsilon_{n i t}=\frac{\partial y_{i t}}{\partial x n_{i t}}=\beta_{n}+\frac{1}{2} \sum_{n=1}^{4} \sum_{m=1}^{4} \beta_{n m} x m_{i t}$.

Output elasticity with respect to each factor of production is estimated as:

$$
\begin{aligned}
& e l=\beta l+2 \beta \text { lll }_{i t}+\beta \text { lcc }_{i t}+\beta \text { lrmrm }_{i t}+\beta \text { lenen }_{i t} \\
& e c=\beta c+2 \beta c c c_{i t}+\beta c l l_{i t}+\beta \text { crmrm }_{i t}+\beta c e n e n_{i t} \\
& \text { erm }=\beta r m+2 \beta \text { rmrmrm }_{i t}+\beta r m l_{i t}+\beta r m c c_{i t}+\beta \text { rmenen }_{i t}
\end{aligned}
$$

$e e n=\beta e n+2 \beta$ enenen $_{i t}+\beta$ enll $_{i t}+\beta$ encc $_{i t}+\beta$ enrmrm $_{i t}$.

The MLE is used to estimate the parameters of Eq. (9) from which the estimates for the output growth and productivity are derived. The coefficients are substituted in Eq. (13)-(16) to obtain $\hat{e}_{L_{i t}}, \hat{e}_{C_{i t}}, \hat{e}_{R M_{i t}}$, and $\hat{e}_{E N_{i t}}$. The average of the input elasticities together with the average of each input growth rates are used to estimate cost shares, input growth effects, and adjusted SE from Eq. (18)-(19).

From TE resulted from Eq. (2) the TEC can be defined as (Khalifah and Abdul Talib, 2008):

$$
T E C=\frac{T E_{i(t+1)}}{T E_{i t}} \text {. }
$$


Output growth $\dot{Y}_{i t}$ is derived by adding input growth $\left(\dot{\Phi}_{t}\right)$, the adjusted scale $\left(e_{t}-1\right) \dot{\Phi}_{t}$, TP, and TEC growth (Liu and Li, 2012). TFP growth captures the output growth after removing the input growth as,

$T \dot{F P}=T P+S C+T E C$.

The input growth and the scale are derived from the input growth variables $(\dot{C}, \dot{L}, R M, \dot{E N})$ as:

$\dot{\Phi}_{i t}=\frac{e_{C_{i t}}}{e_{i t}} \dot{C}_{i t}+\frac{e_{L_{i t}}}{e_{i t}} \dot{L}_{i t}+\frac{e_{R M_{i t}}}{e_{i t}} R \dot{M}_{i t}+\frac{e_{E N}}{e_{i t}} \dot{E N_{i t}}$.

The return to scale variable is computed based on the input elasticities in Eq. (13)-(16):

Scale $_{i t}=\left(e_{i t}-1\right)\left(\frac{e_{C_{i t}}}{e_{i t}} \dot{C}_{i t}+\frac{e_{L_{i t}}}{e_{i t}} \dot{L}_{i t}+\frac{e_{R M_{i t}}}{e_{i t}} \dot{R} \dot{M}_{i t}+\frac{e_{E N}}{e_{i t}} \dot{E} N_{i t}\right)$.

\subsection{Data}

This study looks at 10,607 manufacturing firms in 2007 and 11,590 manufacturing firms in 2013 on the island of Java from 347 five-digit ISIC for the period of 20072013. The data were collected on a yearly basis by the National Statistics Bureau of Indonesia under the national survey for medium and large manufacturing enterprises. The paper classifies firms based on five different criteria. 1) Size, large firms ( $\mathrm{L}$ more than 100 workers) or medium enterprise (ME less than 100). 2) A Capital/Output ratio; low capital (LK) if the ratio is less than $10 \%$, and Capital Intensive (HK) otherwise. 3) Human resource intensity; Human Resource based (HRI) if non-production to production labor is higher than $30 \%$, and Labor Intensive (LI) if the ratio is below $30 \%$. 4) Location (Province within Java Island). Finally, 5) Technology Intensity Definition Classification (Rev 3) based on R\&D intensities: Low Tech (LT), Medium-low Tech (MLT), Medium and High Tech (MHT), and High Tech (HT). MHT includes transport, machinery, and chemicals, while MLT is highly related to a natural resource base (paper, wood, rubber, coke, basic metals, and non-metallic minerals).

The variables employed are Output (Y) in million rupiahs, as the value of goods produced. Capital (C) in million rupiahs for capital goods. Labor (L), total workers per working day. Raw Materials (RM), the value of goods employed as raw material inputs. Energy (EN) in million rupiahs, as the value of energy employed as inputs for the production of Output. Y, C, RM, and EN are deflated by the year 2000 wholesale price index for five-digit ISIC industries.

\section{Results}

The analysis is divided into three parts: in the first part, the regression estimates for the stochastic frontier production are presented, in the second part, the contribution of inputs to output growth is explained, and in the third part, the Total Factor Productivity growth decomposition is presented.

The national survey for medium and large manufacturing firms in Indonesia indicates that from 2009 to 2013, the number of firms decreased, and input to output ratio increased by $8 \%$ (Table A1). Overall employees, value-added output, worker productivity, and production to installed capacity improved. While labor employed increased, it cost firms $27 \%$ more, with worker productivity rising only slightly above the upsurge of labor costs. As most firms in Java are labor-intensive, rises on wages influence firm value-added. Among low tech and medium-low tech firms, the number of enterprises fell, and the total number of employees remained at the nearly same level as 2009. By contrast, large firms saw growth in total workers and industry value-added. Manufacturing might be heading towards higher capital utilization and lower reliance on labor.

\subsection{Stochastic frontier production estimates}

The estimates of the stochastic frontier production of Eq. (9) are displayed in Table 1, helping to observe the technical progress over time. Most of the coefficients are significant applying the $\chi^{2}$ test for nonlinear terms, suggesting that Hicks-neutral function fits better than the Cobb-Douglas (results of five estimates and the LR test available upon request).

The results of the Hicks-neutral model estimation for the SFA demonstrate that the parameters of labor, capital, and raw materials are positive and significant at a level of one percent. If any of those inputs rises, the firm's output will increase. The coefficient of squared inputs is also positive and significant indicating that labor, capital, and raw materials experience increasing returns. The coefficient of the interaction variables between labor-capital and labor-energy are positive and significant, showing a substitution effect. Labor and raw material have complementary effects, denoting a pattern of manufacturing in Indonesia which is intensive in labor and raw materials (natural resources). Capital, on the other hand, has substitute effects with energy inputs.

The time coefficient, employed as a technological progress indicator is significant and positive, indicating a positive TP and a positive relationship with output. Time 
Table 1 Maximum-likelihood estimates for parameters (Hicks-Neutral)

\begin{tabular}{|c|c|c|}
\hline & $\begin{array}{c}\text { Estimates All } \\
\text { Industries }\end{array}$ & $\begin{array}{c}\text { Standard } \\
\text { Errors }\end{array}$ \\
\hline Constant & $3.5926^{* * *}$ & 0.0883038 \\
\hline Labor $(L)$ & $1.7812 * * *$ & 0.0518764 \\
\hline Capital $(K)$ & $0.2188 * * *$ & 0.0092222 \\
\hline Raw Materials $(\mathrm{rm})$ & $0.2670 * * *$ & 0.0088690 \\
\hline Energy (en) & 0.3979 & 0.6567603 \\
\hline Time $(t)$ & $-0.0412 * * *$ & 0.0041494 \\
\hline $\ln L \times \ln L$ & $0.1726^{* * *}$ & 0.0127859 \\
\hline $\ln k \times \ln k$ & $0.009 * * *$ & 0.0003810 \\
\hline $\ln r m \times \ln r m$ & $0.0478 * * *$ & 0.0002710 \\
\hline $\ln e n \times \ln e n$ & -0.3505 & 0.7561559 \\
\hline$t \times t$ & $0.0099 * * *$ & 0.0004928 \\
\hline $\ln L \times t$ & $0.0531 * * *$ & 0.0036214 \\
\hline $\ln k \times t$ & $-0.182 * * *$ & 0.0033939 \\
\hline $\ln r m \times t$ & $0.0185 * * *$ & 0.0019437 \\
\hline $\ln e n \times t$ & $-0.0365^{* * *}$ & 0.0007524 \\
\hline $\ln L \times \ln k$ & $0.0034 * * *$ & 0.0003781 \\
\hline $\ln L \times \ln r m$ & $-0.0103^{* * *}$ & 0.0003779 \\
\hline Sigma-squared $\sigma^{2}$ & $3.1352 * * *$ & 0.0473758 \\
\hline$\lambda$ & $0.9323^{* * *}$ & 0.0014687 \\
\hline$\mu$ & $-3.419 * * *$ & 0.0395796 \\
\hline$\eta$ & $--0.023^{* * *}$ & 0.0026993 \\
\hline Observations & 81.389 & \\
\hline
\end{tabular}

squared is also positive and statistically significant suggesting that TP effect on output will continue playing a role in a positive direction. The estimate of $\mu$ shows that the technical inefficiency term is significant (greater than zero), truncated half-normal distribution. The estimate of time-varying decay parameter $(\eta)$ is negative and significant, indicating a decrease in technical efficiency over time, meaning that firms are lowering their performance over time (getting further away from the production frontier).

\subsection{Input growth analysis}

The nonlinear relationship between inputs and output are displayed in Table 2 together with cost shares, input growth effects, scale effects, elements of Total Factor Productivity, and output growth by technological industry group. Output elasticity with respect to each input denotes the contribution of each input to total output growth. Labor appears in all tech groups as the most important input factor with the largest output elasticity (0.436) while capital (0.002) and raw materials (0.013) have lower elasticity. Energy, by contrast, is negative, pulling down the expansion of output with a large negative elasticity $(-3.097)$. However, the expansion of energy inputs was large, pushing the average total elasticity by $-8 \%$. Labor still represents the main input of production; it is particularly higher for medium size (ME) firms (0.486) over large firms $(0.281)$. However, labor contribution to output growth decreased $22 \%$ from 0.48 in 2007 to 0.36 in 2013. Capital falls from a positive elasticity in 2007 of 0.013 to -0.004 . Overall, raw materials also fall, but remain positive and increasing under MHT, MLT, and HT groups. On average, labor-intensive firms register larger output elasticity with respect to labor, capital, and raw materials. Labor is growing faster (10\%) than capital (less than $1 \%$ ), reinforcing the status as capital saving, and intensive in labor and materials. Raw materials could be associated with competitive resource-based industries (Esquivias, 2017), or by foreign substitutions (imports). However, additional labor, capital, and raw materials do not compensate for the negative effect of energy.

Looking at changes in cost, the increase in energy price and consumption is responsible for 1,214 times the increase of cost, canceling savings in production costs under labor and capital inputs. The cost share of labor and capital decreases firstly because energy costs are now larger, but also because firms may be hiring fewer workers. The share of costs under raw materials is relatively small, possibly indicating that cheaper imports are helping to control a rise in the cost of production. The top nine sectors are dependent on imported materials.

Labor, the primary input of production, has been substituted by capital and larger use of energy. Both the price of energy and the consumption of energy inputs had nearly duplicated from 2000 to 2015 . Sectors particularly affected by the rise in energy prices (more than $100 \%$ ) include the following: instruments (medical, optical, precision); wood, pulp and paper; manufacturing (recycling); textiles, leather and footwear; motor vehicles and basic metals. A higher cost of inputs also places pressure on the ability to upgrade industrial activities.

The input growth effect analysis indicates the contribution of input growth to total output. Growth in inputs of production still accounts for the largest contributor to output growth, equal to $28.4 \%(\Phi)$, in line with conventional growth theory, meaning that having a large labor force, abundant materials, more capital, and more accessible energy is driving nearly $30 \%$ of industrial growth. Energy represents the largest contributor to output expansion with an impact on output growth of 0.366 , while labor, capital, and materials contribute positively but they are experiencing a negative trend. However, combined inputs 
Table 2 Growth decomposition for three industrial groups (average 2007-2013)

\begin{tabular}{|c|c|c|c|c|c|c|c|c|c|}
\hline & \multicolumn{5}{|c|}{ Output Elasticity } & \multicolumn{4}{|c|}{ Cost Share } \\
\hline & $e_{L}$ & $e_{K}$ & $e_{R M}$ & $e_{E N}$ & $e_{\text {Total }}$ & $s_{L}$ & $s_{K}$ & $s_{R M}$ & $s_{E N}$ \\
\hline LT & 0.423 & -0.007 & 0.025 & -2.988 & -2.547 & -0.096 & 0.051 & 0.005 & 1.040 \\
\hline MHT & 0.319 & -0.023 & -0.025 & -3.379 & -3.107 & -0.153 & -0.162 & 0.059 & 1.256 \\
\hline MLT & 0.544 & 0.055 & -0.026 & -3.478 & -2.906 & -0.081 & 0.272 & -0.013 & 0.822 \\
\hline HT & 0.353 & -0.042 & -0.011 & -2.971 & -2.671 & -0.189 & -0.014 & 0.012 & 1.190 \\
\hline \multirow[t]{3}{*}{ Total } & 0.436 & 0.002 & 0.013 & -3.097 & -2.646 & -0.154 & -0.106 & 0.046 & 1.214 \\
\hline & \multicolumn{7}{|c|}{ Input Growth Effect } & \multicolumn{2}{|c|}{ Scale Effect (\% } \\
\hline & $s_{L} \dot{L}$ & $s_{K} \dot{K}$ & $s_{R M} R \dot{M}$ & $s_{E N} \dot{E N}$ & $\dot{\phi}$ & \multicolumn{2}{|c|}{$e-1$} & \multicolumn{2}{|c|}{$(e-1) \dot{\phi}$} \\
\hline HT & -0.027 & 0.023 & -0.149 & 0.676 & 0.524 & \multicolumn{2}{|c|}{-3.547} & \multicolumn{2}{|c|}{-1.859} \\
\hline LT & -0.051 & -0.028 & -0.016 & 0.365 & 0.270 & \multicolumn{2}{|c|}{-4.107} & \multicolumn{2}{|c|}{-1.109} \\
\hline MHT & -0.004 & -0.005 & -0.065 & 0.842 & 0.768 & \multicolumn{2}{|c|}{-3.906} & \multicolumn{2}{|c|}{-3.000} \\
\hline MLT & -0.006 & 0.005 & -0.023 & 0.175 & 0.150 & \multicolumn{2}{|c|}{-3.671} & \multicolumn{2}{|c|}{-0.551} \\
\hline \multirow[t]{3}{*}{ Total } & -0.040 & -0.020 & -0.022 & 0.366 & 0.284 & \multicolumn{2}{|c|}{-3.646} & \multicolumn{2}{|c|}{-1.036} \\
\hline & $\dot{\phi}$ & Scale & $\dot{T E}$ & $\Delta \delta_{t}$ & $\dot{T F P}$ & Estimated $\dot{Y}$ & Actual $\dot{Y}$ & \multicolumn{2}{|c|}{$Y-\dot{Y}$} \\
\hline & 1 & 2 & 3 & 4 & $(2+3+4)$ & 6 & 7 & \multicolumn{2}{|c|}{$(7-6)$} \\
\hline HT & 0.524 & -2.187 & -0.008 & 0.050 & -2.145 & -1.671 & 0.218 & \multicolumn{2}{|c|}{1.889} \\
\hline LT & 0.270 & -1.239 & -0.011 & 0.046 & -1.204 & -0.980 & 0.137 & \multicolumn{2}{|c|}{1.117} \\
\hline MHT & 0.768 & -2.589 & -0.007 & 0.051 & -2.545 & -1.829 & 0.216 & \multicolumn{2}{|c|}{2.044} \\
\hline MLT & 0.150 & -1.156 & -0.009 & 0.047 & -1.118 & -1.015 & 0.136 & \multicolumn{2}{|c|}{1.151} \\
\hline Total & 0.284 & -1.323 & -0.011 & 0.047 & -1.287 & -1.049 & 0.143 & \multicolumn{2}{|c|}{1.192} \\
\hline
\end{tabular}

Notes: $e K$ Elasticity of Output with respect to capital, $e L$ elasticity labor, $e R M$ elasticity raw materials, $e E N$ elasticity energy, $e$ Total Elasticity of Output. $\dot{\phi}$ Input growth Adjusted scale effect (Scale or SEC), change in Technical Efficiency (TE), and Technical Progress $\left(\Delta \delta_{t}\right)$. Estimated $(Y)$ estimated growth of output. $(\dot{Y})$ is the actual output growth

are not able to create an additional impact through scale effects as they are facing a negative contribution to output. The negative scale indicates that Indonesia does not take full advantage of the abundant supplies available in the country. There is no evidence then of scale effects as an alternative source of growth in Indonesia. MHT firms have the largest negative scale effects, which involves most of the new industries in the country (automotive, electronics, and machinery). Comparative advantage in Java seems to remain in lower-skilled industries, less intensive in energy use and saving with imported or abundant local raw materials. The country may be losing in traditionally labor-intensive sectors (textiles, food, and footwear) where nearly $80 \%$ of total labor is employed.

\subsection{TFP growth decomposition}

The lower section of Table 2 illustrates the decomposition of Total Factor Productivity (TFP) into technical efficiency change, scale effects, and technological progress based on the industrial technological group, similar to Table 3 and Table 4 that summarize at different group levels. Average Technical Efficiency (TE) in Table 3 shows a negative trend in values over time. Average efficiency of $65.9 \%$ means that nearly $35 \%$ of production is lost due to firm-specific inefficiencies and white noise. Across firms, TE ranges from 0.746 ( $74.6 \%$ highest) in MHT industries to the lowest $64.2 \%$ of efficiency in the Low-Tech groups (food, textile, and footwear. By tech groups, LT reports the lowest TE; meanwhile, MHT and HT report $13 \%$ to $17 \%$ higher TE than average. Low capital-intensive firms, particularly those employing HRI, are enjoying the most substantial growth in TE. Skills might be an essential contributor to higher TE. Sectors like motor vehicles, leather and beverages have slightly larger TE ( $3 \%$ to $4 \%$ ) than more traditional sectors in Indonesia like apparel, textiles, tobacco or chemicals.

Technical efficiency changes (TEC) can be interpreted as the rate at which an entity moves towards or away from the production frontier. Technical efficiency change for manufacturing is negative by a low $-0.011 \%$. Low TEC indicates that firms are missing opportunities to better use inputs of production. Over time, all groups of firms 
Table 3 Growth Decomposition for The Aggregates and Three Industrial Groups.

\begin{tabular}{llccccccc}
\hline \multirow{2}{*}{ Size } & & TE & TEC & TP & SEC & TFP Avrg & TFP 07-08 & TFP 12-13 \\
\hline \multirow{2}{*}{ Technology } & Medium & 0.659 & -0.011 & 0.044 & -1.116 & -1.083 & -0.818 & -2.170 \\
& Large & 0.660 & -0.011 & 0.054 & -1.938 & -1.895 & -1.461 & -3.556 \\
& HT & 0.714 & -0.008 & 0.050 & -2.187 & -2.145 & -2.153 & -4.699 \\
& LT & 0.642 & -0.011 & 0.046 & -1.239 & -1.204 & -0.887 & -2.389 \\
& MHT & 0.746 & -0.007 & 0.051 & -2.589 & -2.545 & -2.747 & -2.711 \\
\multirow{2}{*}{ Average Total } & MLT & 0.698 & -0.009 & 0.047 & -1.156 & -1.118 & -0.599 & -2.978 \\
\hline
\end{tabular}

Notes. See notation in Table 2 and Table 4.

are experiencing negative TEC with LT firms suffering a more significant loss. LT firms account for $72 \%$ of the total sample of the manufacturing sector.

As regards technological progress, TP, which involves shifts of the production function over time, medium size companies are experiencing slightly higher TP than large firms. Labor intensive firms have lower TP (0.046) than average, although TP appears low and relatively similar across industries. All four tech groups improve their TP values over time. However, as all other components of TFP are negative, the TP rate growth is not enough to catch-up in TFP growth.

Scale component refers to the contribution of factors of production (all together) to output growth, to the relative variation in the output due to changes in factors of production, or to lower average cost due to higher output. Overall, the scale effect is the concept that most influences the negative values in TFP growth. Larger differences in performance across tech groups are shown in the scale effects; particularly large firms combining HighTech or MHT face a -1.938 negative scale effect. The low-tech, less skill-intensive, and smaller firms are those groups with the smallest adverse scale effects, as well as the highest average TFP (smallest negative TFP). Most of the Indonesian firms are within those groups, signaling that advantage is within those specific groups. However, a significant number of MEs employing the vast majority of workers in the country are experiencing a negative scale, meaning that more massive inputs are being allocated in MEs, but the output is contracting. While a vast expansion of inputs, a large labor pool and abundance of resources could allow manufacturing to rise due to scale effects, in fact, it is slowing down due to a rise in prices and low efficiency. It is also noticeable that scale effects were more than three times lower in 2013 than in 2007.

Table A2 displays the estimations for the nine top industrial sectors in Indonesia (65\% of total players), highly dependent on imported intermediate materials, contributing to nearly $80 \%$ of total industrial output and absorbing $65 \%$ of the workforce. More traditional sectors in Indonesia like food, textiles, and chemicals report the largest negative effects of scale component. On the contrary, more recent sectors employing larger capital, more skillful workers, and more globally integrated experience fewer negative effects in scale (electronic and transportation). Nevertheless, those more productive sectors experience greater negative effects due to scale towards the last period, possibly affected by the massive increase in input costs.

Looking at TFP growth, all the four tech-groups meet negative growth rates, on average $-1.287 \%$ a year, although LT and MLT register higher TFP performance over higher-tech firms. The low-tech, less skill-intensive, and medium-sized firms have the highest average TFP. By firm size, medium firms reported smaller negative TFP growth with -1.083 versus -1.895 in large ones. As the large majority of workers (72\%) are working for ME firms, this might allow them to expand faster than large ones.

Manufacturing experienced positive output growth through the conventional sources of growth, technical progress and larger inputs of production. However, the country experienced negative growth in alternative sources, scale, and technical efficiency. Actual industrial output expansion is positive at $0.143 \%$, while the estimated expansion of output is negative at $-1.049 \%$. LT and MLT register the lowest output expansion, while HT and MHT experience almost double rates of output growth.

Table 3 indicates the TE, TEC, TP, SEC, and TFP based on the tech group, size, and Human Resources combined. Differences in firm performance are observed when factors are combined. In general, firms with higher skills capture larger TE, lower negative TEC, and higher TP over labor-intensive firms, indicating potential gains in input efficiency and output expansion by supporting human 
Table 4 Growth Decomposition for The Aggregates and Three Industrial Groups

\begin{tabular}{|c|c|c|c|c|c|c|c|c|c|c|c|c|}
\hline \multirow{2}{*}{$\mathrm{ME}$} & & \multicolumn{2}{|c|}{$\mathrm{TE}$} & \multicolumn{2}{|c|}{ TEC } & \multicolumn{2}{|c|}{$\mathrm{TP}$} & \multicolumn{2}{|c|}{ SEC } & \multicolumn{3}{|c|}{ TFP } \\
\hline & & $\mathrm{L}$ & $\mathrm{ME}$ & $\mathrm{L}$ & $\mathrm{ME}$ & $\mathrm{L}$ & $\mathrm{ME}$ & $\mathrm{L}$ & $\mathrm{ME}$ & $\mathrm{L}$ & Avg & \\
\hline \multirow{2}{*}{ HT } & LI & 0.701 & 0.680 & -0.008 & -0.010 & 0.046 & 0.056 & -0.831 & -3.603 & -0.794 & -3.558 & -2.176 \\
\hline & HRI & 0.767 & 0.734 & -0.006 & -0.008 & 0.047 & 0.056 & -1.602 & -4.820 & -1.562 & -4.772 & -3.167 \\
\hline \multirow{2}{*}{ LT } & LI & 0.635 & 0.631 & -0.011 & -0.012 & 0.044 & 0.053 & -1.308 & -1.871 & -1.276 & -1.829 & -1.552 \\
\hline & HRI & 0.667 & 0.657 & -0.010 & -0.010 & 0.045 & 0.054 & -0.451 & -1.296 & -0.416 & -1.252 & -0.834 \\
\hline \multirow{2}{*}{ MHT } & LI & 0.739 & 0.737 & -0.007 & -0.008 & 0.046 & 0.056 & -2.306 & -3.663 & -2.267 & -3.615 & -2.941 \\
\hline & HRI & 0.760 & 0.742 & -0.007 & -0.007 & 0.048 & 0.055 & -1.591 & -3.381 & -1.550 & -3.333 & -2.442 \\
\hline \multirow{2}{*}{ MLT } & $L I$ & 0.703 & 0.675 & -0.009 & -0.010 & 0.044 & 0.054 & -0.664 & -2.567 & -0.629 & -2.523 & -1.576 \\
\hline & HRI & 0.707 & 0.682 & -0.009 & -0.011 & 0.047 & 0.055 & -1.529 & -1.396 & -1.491 & -1.353 & -1.422 \\
\hline \multicolumn{2}{|c|}{ Average Total } & 0.659 & 0.660 & -0.011 & -0.011 & 0.044 & 0.054 & -1.116 & -1.938 & -1.083 & -1.895 & -1.489 \\
\hline
\end{tabular}

Notes. High Technology (HT), Low Tech (LT), Medium-High Tech (MHT), and Medium-Low Tech (MLT), Large Size (L), Medium Size Enterprise (ME), Labor Intensive (LI), Human Resource base (HRI)

capital. Large firms under LT and MT groups face lower negative scale effects and lower TFP growth.

Firms combining Low-Tech and high capital to output ratio have the lowest TE. Low capital-intensive industries, particularly those employing higher-skilled workers (HRI) are gaining the largest growth in TE. Three groups of firms offer higher TE performance than average: 1) High-Tech, Labor-Intensive, and Medium-size firms perform $47 \%$ better; 2) Low-Tech, higher skill (HRI), and MEs (72 \% performance); 3) Medium Low-Tech, Labourintensive, and $\mathrm{ME}$ have $58 \%$ higher TE performance.

Indonesia experienced meaningful increases in inputs of production throughout the period of analysis. Output expanded at $278 \%$ (constant prices), physical capital registered an expansion of $157 \%$, total labor also reached $248 \%$ growth, raw materials expanded by $223 \%$, and energy (constant prices) rose by $256 \%$. The expansion of inputs is relatively similar to that of output. Prices in labor and energy increase in an important way, perhaps canceling possible savings due to more productive use of inputs (mainly saving in capital). This might also indicate a positive impact on wages (welfare for workers), and a lower burden to government as the subsidies in energy also fell substantially, releasing fiscal pressures. Besides larger inputs and technological gains, other aspects such as quality of inputs and more innovation can help to grasp more benefits from abundant resources and untapped new sources of growth, as noted in (Ehrenberger et al., 2015).

Across the six provinces within Java, industry concentrates $34 \%$ of output in West Java, followed by East Java (20\%), and Central Java (20\%). Large firms have higher productivity performance, while outside Jakarta medium-size firms report larger TFP growth. While TE,
TEC, and TP is similar across provinces, they have a different capacity to absorb new factors of production and in technological capability. In higher technological industries, DKI Jakarta has lower average elasticity of output. East Java and DIY report higher elasticity of inputs, either because they are less intensive in energy or wages are lower. Nevertheless, all provinces lower their efficiency over time, while they slightly improve in TP. Larger differences in performance occur under scale effects.

\section{Conclusions}

This article deconstructs and analyses the elements of growth of the manufacturing corridor of Indonesia (for the island of Java) from 2007 to 2013. Manufacturing firms are categorized based on location, size, technology, skills, and the ratio of capital/output. Labor remains as the most crucial input with the largest elasticity to output 0.436 , while capital (0.002) and raw materials (0.013) have lower elasticity. Energy has a large and negative elasticity (-3.097), canceling the positive effects of other inputs, responsible for $121 \%$ of the increase in industry costs. Input growth is the main source of output expansion (0.284) with energy registering the largest increase, both in volume and prices. Labor has a complementary effect with materials, but a substitution effect with energy and capital, probably causing a shift from labor-intensive to more capital-intensive activities. Industry is capital saving, with a higher impact on medium-size firms.

Comparative advantage in Java seems to be in lower-skilled firms and those less intensive in energy use. Low-tech, less skill-intensive, and medium-size firms reported the highest average TFP. Low capital-intensive firms, mostly those employing higher skills, have 
the largest growth in Technical Efficiency (TE) and best Technical Efficiency Change performance. Skills might be an important factor to increase TE in firms competing in low production cost. Firms with larger human skills capture larger TE and higher TP over labor-intensive firms. However, firms under the category of high skills reported larger negative scale effects. Labor intensive firms are less efficient but were less exposed to impacts due to energy prices.

Advice for policymakers could be: 1) absorbing a large number of unskilled workers under Medium-size firms and Labor-Intensive, and; 2) increased skills in Low-Tech could help raise TFP growth. Gains from scale can be achieved under Labor-Intensive and medium-size firms, while gains in efficiency and technological progress TP can be achieved in higher-skilled (HRI) and large-size firms. Low-Tech has the best performance. However, for the last two periods, all tech groups experienced a worsening in

\section{References}

Aigner, D., Knox Lovell, C. A., Schmidt, P. (1977) "Formulation and estimation of stochastic frontier production function models", Journal of Econometrics, 6(1), pp. 21-37.

https://doi.org/10.1016/0304-4076(77)90052-5

Aswicahyono, H., Hill, H. (2002) "'Perspiration' vs 'Inspiration' in Asian Industrialisation: Indonesia Before the Crisis", The Journal of Development Studies, 38(3), pp. 138-163. https://doi.org/10.1080/00220380412331322381

Aswicahyono, H., Hill, H., Narjoko, D. (2010) "Industrialisation after a Deep Economic Crisis: Indonesia", The Journal of Development Studies, 46, pp. 1084-1108. https://doi.org/10.1080/00220380903318087

Battese, G. E., Coelli, T. J. (1995) "A model for technical inefficiency effects in a stochastic frontier production function for panel data", Empirical Economics, 20(2), pp. 325-332. https://doi.org/10.1007/BF01205442

Ben-Belhassen, B., Womack, A. W. (2000) "Measurement and Explanation of Technical Efficiency in Missouri Hog Production", presented at 2000 Annual meeting, July 30-August 2, 2000, Tampa, FL, USA.

Coelli, T. J., Prasada Rao, D. S., Battese, G.E. (1998) "An Introduction to Efficiency and Productivity Analysis", Springer, Boston, MA, USA.

https://doi.org/10.1007/978-1-4615-5493-6

Ehrenberger, M., Koudelkova, P., Strielkowski, W. (2015) "Factors Influencing Innovation in Small and Medium Enterprises in the Czech Republic", Periodica Polytechnica Social and Management Sciences, 23(2), pp. 73-83.

https://doi.org/10.3311/PPso.7737

Esquivias, M. A. (2017) "The Change of Comparative Advantage of Agricultural Activities in East Java Within the Context of Asean Economic Integration", AGRIS on-line Papers in Economics and Informatics, 9(1), pp. 33-47.

https://doi.org/10.7160/aol.2017.090103
Total Factor Productivity (TFP) performance, particularly due to a negative scale effect. While positive impacts might happen in the form of higher wages and lower energy subsidies, increases in productivity might allow a more balanced growth. Labor still represents the main input of production with larger output elasticity under Medium Size firms rather than large ones. However, the elasticity with respect to labor fell by $22 \%$, signaling possible industrial slowdown and poor complementation of inputs. The manufacturing sector seems to be missing a decade of abundance in resources due to poor productive performance.

\section{Acknowledgement}

The project presented in this article is supported by the Direktorat Riset dan Pengabdian Masyarakat, Direktorat Jenderal Penguatan Riset dan Pengembangan Kementerian Riset, Teknologi, dan Pendidikan Tinggi Republik Indonesia.

Esquivias, M. A. (2018) "East Java’s Productivity Growth: Evidence of Industrialization or Deindustrialization in East Java (Indonesia)?", East Java Economic Journal, 2(2), pp. 13-38.

Green, P. J. (1990) "On Use of the Em Algorithm for Penalized Likelihood Estimation", Journal of the Royal Statistical Society: Series B Statistical Methodology, 52(3), pp. 443-452. https://oi.org/10.1111/j.2517-6161.1990.tb01798.x

Han, G., Kalirajan, K., Singh, N. (2002) "Productivity and economic growth in East Asia: innovation, efficiency and accumulation", Japan and the World Economy, 14(4), pp.401-424. https://doi.org/10.1016/S0922-1425(02)00028-2

Heriqbaldi, U., Purwono, R., Haryanto, T., Primanthi, M. R. (2015) "An Analysis of Technical Efficiency of Rice Production in Indonesia", Asian Social Science, 11(3), pp. 91-102. https://doi.org/10.5539/ass.v11n3p91

Hill, H., Kalirajan, K. P. (1993) "Small enterprise and firm-level technical efficiency in the Indonesian garment industry", Applied Economics, 25(9), pp. 1137-1144. https://doi.org/10.1080/00036849300000174

Kalirajan, K. P., Shand, R. T. (1994) "Economics in disequilibrium: an approach from the frontier", MacMillan India, Delhi, India.

Khalifah, N.A., Abdul Talib, B. (2008) "Are foreign multinationals more efficient? A stochastic production frontier analysis of Malaysia's automobile industry", International Journal of Management Studies (IJMS), 15, pp. 91-113.

Kumbhakar, S. C., Knox Lovell, C. K. (2003) "Stochastic frontier analysis", Cambridge University Press, Cambridge, UK.

Li, K.-W., Liu, T. (2011) "Economic and productivity growth decomposition: An application to post-reform China", Economic Modelling, 28(1-2), pp. 366-373. https://doi.org/10.1016/j.econmod.2010.08.013

Liu, T., Li, K.-W. (2012) "Analyzing China's productivity growth: Evidence from manufacturing industries", Economic Systems, 36(4), pp. 531-551.

https://doi.org/10.1016/j.ecosys.2012.03.003 
Margono, H., Sharma, S. C. (2006) "Efficiency and productivity analyses of Indonesian manufacturing industries", Journal of Asian Economics, 17(6), pp. 979-995.

https://doi.org/10.1016/j.asieco.2006.09.004

Margono, H., Sharma, S. C., Sylwester, K., Al-Qalawi, U. (2011) "Technical efficiency and productivity analysis in Indonesian provincial economies", Applied Economics, 43(6), pp. 663-672. https://doi.org/10.1080/00036840802599834

Mokhtarul Wadud, I. K. M. (2004) "Technical Efficiency in Australian Textile and Clothing Firms: Evidence From the Business Longitudinal Survey", Australian Economic Papers, 43(3), pp. 357-378.

https://doi.org/10.1111/j.1467-8454.2004.00235.x

Oh, D., Heshmati, A., Lööf, H. (2014) "Total factor productivity of Korean manufacturing industries: Comparison of competing models with firm-level data", Japan and the World Economy, 30, pp. 25-36. https://doi.org/10.1016/j.japwor.2014.02.002

Saliola, F., Seker, M. (2011) "Total factor productivity across the developing world", The World Bank, Rep. 68273.

Sari, D. W., Khalifah, N. A., Suyanto, S. (2016) "The spillover effects of foreign direct investment on the firms' productivity performances", Journal of Productivity Analysis, 46(2-3), pp. 199-233. https://doi.org/10.1007/s11123-016-0484-0
Sheng, Y., Song, L. (2013) "Re-estimation of firms' total factor productivity in China's iron and steel industry", China Economic Review, 24, pp. $177-188$.

https://doi.org/10.1016/j.chieco.2012.12.004

Solow, R. M. (1957) "Technical Change and the Aggregate Production Function", The Review of Economics and Statistics, 39(3), pp. 312-320.

https://doi.org/10.2307/1926047

Sugiharti, L., Purwono, R., Primanthi, M. R., Esquivias, M.A. (2017) "Indonesian Productivity Growth: Evidence from the Manufacturing Sector in Indonesia", Pertanika Journal of Social Science and Humanities, 25, pp. 29-44.

Suyanto, S., Salim, R. A., Bloch, H. (2009) "Does Foreign Direct Investment Lead to Productivity Spillovers? Firm Level Evidence from Indonesia", World Development, 37(12), pp. 1861-1876. https://doi.org/10.1016/j.worlddev.2009.05.009

Timmer, M. P. (1999) "IIndonesia's Ascent on the Technology Ladder: Capital Stock and Total Factor Productivity in Indonesian Manufacturing, 1975-95", Bulletin of Indonesian Economic Studies, 35(1), pp. 75-97.

https://doi.org/10.1080/00074919912331337497

Verbeek, M. (2008) "A guide to modern econometrics", John Wiley \& Sons, Chichester, UK.

\section{Appendix}

Table A1 Statistical Performance of the National Manufacturing Industry Indonesia (2009 and 2013)

\begin{tabular}{lcccccccc}
\hline \multirow{2}{*}{$\begin{array}{l}\text { Technology (T) / } \\
\text { Size (S) }\end{array}$} & \multicolumn{2}{c}{ Total Number of firms } & \multicolumn{2}{c}{$\begin{array}{c}\text { Total Number of } \\
\text { employees }\end{array}$} & \multicolumn{2}{c}{$\begin{array}{c}\text { Industry Value Added } \\
\text { (Billion Rupiah) }\end{array}$} & \multicolumn{2}{c}{$\begin{array}{c}\text { Worker Productivity } \\
\text { (1,000 Rupiah) }\end{array}$} \\
\cline { 2 - 9 } & $\mathbf{2 0 0 9}$ & 2013 & 2009 & 2013 & 2009 & 2013 & 2009 & 2013 \\
\hline Low (T) & 16.855 & 16.024 & 293 & 337 & 358.164 & 713.174 & 1.452 .461 & 2.213 .365 \\
Large (S) & 4.171 & 4.401 & 246 & 291 & 331.139 & 665.266 & 1.599 .210 & 2.396 .900 \\
Medium (S) & 12.684 & 11.623 & 46 & 46 & 27.023 & 47.908 & 699.326 & 1.152 .173 \\
Med-Low (T) & 4.553 & 4.646 & 70 & 80 & 132.331 & 243.035 & 1.373 .875 & 2.136 .434 \\
Large (S) & 1.371 & 1.483 & 58 & 66 & 119.872 & 216.499 & 1.546 .756 & 2.400 .088 \\
Medium (S) & 3.182 & 3.163 & 13 & 14 & 12.46 & 26.538 & 862.637 & 1.420 .877 \\
Medium-High (T) & 2.557 & 2.943 & 67 & 82 & 304.898 & 516.497 & 3.559 .452 & 3.941 .711 \\
Large (S) & 1.143 & 1.199 & 61 & 73 & 290.793 & 477.844 & 3.801 .077 & 4.112 .900 \\
Medium (S) & 1.414 & 1.744 & 6 & 9 & 14.104 & 38.653 & 1.213 .515 & 2.813 .645 \\
TOTAL & 23.965 & 23.613 & 431 & 499 & 795.393 & 1.472 .706 & 6.385 .788 & 8.291 .510 \\
\hline
\end{tabular}

Source. Data from the Indonesian National Bureau of Statistics, Badan Pusat Statistik (BPS).

Table A2 Growth Decomposition for the Aggregates by Industry (Nine TOP Sectors)

\begin{tabular}{lccccccc}
\hline & TE & TEC & TP & SEC & TFP Avrg & TFP 07-08 & TFP 12-13 \\
\hline Food, beverages & 0.655 & -0.011 & 0.046 & -1.472 & -1.437 & -0.790 & -2.570 \\
Tobacco & 0.674 & -0.011 & 0.046 & -0.941 & -0.906 & -0.851 & -3.022 \\
Textile, leather, footwear & 0.656 & -0.011 & 0.047 & -1.019 & -0.983 & -1.247 & -1.677 \\
Chemicals & 0.645 & -0.011 & 0.047 & -1.287 & -1.251 & -1.127 & -2.795 \\
Metals & 0.668 & -0.010 & 0.047 & -0.851 & -0.814 & -0.470 & -2.873 \\
Fabricated Metals & 0.664 & -0.010 & 0.047 & -1.096 & -1.059 & -0.483 & -3.530 \\
Electrical equipment & 0.668 & -0.010 & 0.047 & -0.229 & -0.192 & -2.360 & -2.806 \\
Motor vehicles & 0.668 & -0.009 & 0.046 & -0.745 & -0.708 & -0.023 & -3.663 \\
Average & 0.659 & -0.011 & 0.047 & -1.323 & -1.287 & -0.790 & -2.570 \\
\hline
\end{tabular}

